\title{
Digital Emporiums: Platform Capitalism in India ${ }^{1}$
}

\author{
Adrian Athique ${ }^{2}$ \\ THE UNIVERSITY OF QUEENSLAND \\ a.athique [AT] uq.edu.au
}

\begin{abstract}
Taking the historical example of the emporium, this article attempts to situate India's emerging platform economy within the historical evolution of market exchange in the subcontinent. I argue that the market systems constituted by media platforms are, like all markets within a true economy, significantly dependent upon their interaction with other markets. In India, this includes the aggregation of erstwhile media industries along with informal markets for "services," increasingly under the aegis of finance capital and the operators of mobile digital infrastructure. From this wider perspective, we can trace the expansion of a "mediated economy" through which an increasing number of economic exchanges are being aggregated within portals that allow value capture at the transactional level. By emphasizing the evolutionary processes at work in the platform economy, this article also seeks to illustrate how the digital economy is shaped by pathways established within the distinctive economics of media systems.
\end{abstract}

Keywords: Platform Capitalism; Digital Economy; Digital Transactions; Media Industries; India

\section{Emporium Redux}

In Janpath, a major thoroughfare at the heart of Lutyen's New Delhi, stands a series of stateoperated emporiums offering goods from across India. In a concretization of the political and economic relationships of the 1970s, the row of emporiums offering wares from specific Indian states sits across the road from the towering structure of the All India Central Cottage Industries Emporium. As reminders of the heyday of the command economy era under Indira Gandhi, Delhi's handicraft emporiums continue to offer customers a consciously curated array of goods, enclosed within a tightly regulated space where the inefficiencies and hassles 
of everyday exchange are negated by the standardization of both prices and goods under the aegis of the state. They also deliver. A reminder of the rational promises of a receding era, these emporiums in turn reference the retail emporiums that appeared in global metropoles at the end of the nineteenth century, heralding the era of the urban department store. Beyond its historical resonance as a grandiose sensory-retail experience, I propose that the emporium might serve us well as both a metaphor and a structural analogy for India's emerging "platform economy." I do so for the following reasons:

1. The emporium pioneered a multiproduct retail space with disparate supply chains, thereby marking the historical co-evolution of the colonial bazaar and global trade.

2. The emporium materialized the enclosure of goods and services under a branded banner, thereby reflecting the commanding logics of aggregation and enclosure evident in platform business models.

3. The emporium showcased the diversity of product origins, cultural markets, and social transactions being captured, foreshadowing the dynamics of discovery in the platform economy.

4. The emporium responded to the densification and machination of urban life, thereby occupying a central position around which transport, entertainment, and service economies were organized.

5. The emporium evolved, via Fordism, into the modern department stores that introduced the system of cashless transactions that enable platform businesses in the present era.

6. The emporium, by its very nomenclature, referenced the capacity of privatized markets to determine both products and subjects, thereby echoing the foundation of modern India on the commercial sovereignty of the Company Raj.

Amid the discourses of novelty and disruption circulating in both public and private sector offices regarding the disruptive effects of Digital India, this more evolutionary perspective provides an alternative starting point for our discussion of India's platform economy. It allows us to situate "platform capitalism" as a phenomenon emerging from the extension and convergence of long-term tendencies in media markets. It also calls for a substantially sui generis approach to platform capitalism in India, on the basis that platform economies tend to "platformize" existing market exchanges rather than fashion new objects of exchange. As Julie Cohen puts it, "platforms do not enter or expand markets; they replace (and rematerialize) them."3 For this reason, internet-enabled platforms are perhaps best understood as attempts to constitute a transactional layer over and above existing markets and social relations. ${ }^{4}$ In a structural sense, the major platforms operating across different service domains are seeking to establish proprietary markets, or "ecospheres," within the commercial geography of India. Such ambitions are, of course, quite familiar and consistent with India's economic history. Equally, while the rapid "platformization" of peer-to-peer exchanges may well be novel in devices, scope, and form, the multisided market logics of platform businesses clearly extend tendencies long evident in media economies. ${ }^{5}$ Due to the intrinsically embedded nature of mediation within social processes, the substantive point of novelty may well be the protocols through which digital platforms are effectively channeling India's 
informal and social economies. ${ }^{6}$ It makes good sense, then, to consider India's platform economy not solely in terms of "disruption" but more substantially through the pathways of evolutionary process.

\section{Digital Emporiums}

In a fairly literal sense, we can apply the structural analogy of the emporium by demonstrating the continuation of its major vectors in the development of India's platform economy. The most obvious examples of the multiproduct marketplace are in e-commerce, including the Amazon-inspired Flipkart platform and Amazon itself in its Indian manifestation (although spiritual guru Baba Ramdev's Patanjali platform also spreads itself impressively across an array of devotional, nutritional, and digital products and services, even without his novel social media app Khumboo). ${ }^{7}$ As Pradip Thomas has noted, the looming enclosure of India's vast middle class of small-scale producers and retailers within the online retail space has been figured as both an economic and a political threat by influential components within the ruling Bharatiya Janata Party (BJP). ${ }^{8}$ At the same time, Indian retailers have proved adept in marketing their own goods worldwide through global platform outlets, while the Government of India has moved somewhat erratically between regulatory protection for local producers and regulatory loopholes, allowing Walmart and Amazon to establish a duopoly in the servicing of online distribution. ${ }^{9}$ This equivalence stems not only from overlapping and outmoded ministerial jurisdictions, but directly from the Government of India's reliance on technology companies to provide the pipes and platforms necessary for realizing its Digital India vision of aggregated and automated governance. ${ }^{10}$ Beyond the virtualization of the everyday marketplace, the mutual constitution of retail and service platforms invariably brings together goods, labor, and cultures from across India, as the state emporiums once did, but now recasts the retail space across the larger pan-Indian space previously offered up as a metropolitan fantasy. Where the consumer was once configured as a benevolent bureaucrat or international tourist, the all-India market array is now configured for the benefit of the urban middle-class consumers mobilized through three decades of liberalization. ${ }^{11}$

The orientation of platforms offering services (such as food, taxis, domestic labor) and the offering of platforms selling goods (with their multiple tie-up offers for film tickets, virtual cashback, and coffee vouchers) make it clear that their marketing logics firmly position customers within an urban leisure economy. ${ }^{12}$ Nonetheless, like the erstwhile colonial bazaar described by Ray, Bannerjee, Chakrabarti and others, the wider platform ecology also brings a proliferation of communities and cultures into contact via open platforms such as WhatsApp and YouTube..$^{13}$ In the latter case, intensely local popular cultures across India have established channels alongside the exotica of foreign content that lures urban elites to Netflix. ${ }^{14}$ As meeting points for so many vernaculars of culture and commerce, the usergenerated content (UGC) platforms are unruly spaces where the sensorial spectrum of the digital breaks through the logics of aggregation in all directions. ${ }^{15}$ At the back end, the new market regimes for platform labor (i.e., for cooks, drivers, guards, and maids) instituted by service platforms such as Zomato, Ola, and UrbanClap link them directly to the stratified layers of India's informal economy. In doing so, the complex relationships between 
improvisational and marginal spaces of the digital and the affordances of automated consumers armed with smartphones are remediating power and precarity through new forms of algorithmic discipline. ${ }^{16}$ A gig economy is, of course, nothing new to India's expansive pool of marginal and migrant labor, but the rating of their daily fortunes by digital brands makes these entities curators of the informal sector in much the same fashion that state emporiums were once the curators of village handicrafts.

Platforms operationalize machine logics of efficiency and control, but, like emporiums before them, they furnish a distinct set of transactional logics. Automation is deployed to increase the scale, scope, speed, and volume of transactions, and an important element of this is the centralization of money exchanges. ${ }^{17}$ A key component of the architecture of emporiums was their central payments space, and mobile payment systems occupy this critical space within the ecology of platforms. Thus, we also have to understand the emporium and the platform as vast mechanisms for handling money. The aggregation of cash fosters market power and the ability to carry loss-leaders, paving the way for regimes of brand loyalty embedded in the expansion of consumer credit. In the Indian context, where the vast bulk of petty exchanges have operated in the informal and untaxed sector, the imposition of central accounting regimes also constitutes an overarching "mechanism of legibility" that scrutinizes even the smallest symptom of leakage. The production of transaction records is itself central to the business of governance, and the capacity of mobile payment systems to provide integrated individualized transaction records makes them intrinsic to the nervous system of the state. No one doubts that the near-simultaneous launch of mobile money platforms such as Paytm in 2015 and the shock demonetization of the cash supply in 2016 were conjoint processes. ${ }^{18}$ State patronage for a "cashless India" is reciprocated by the sharing of transaction data, where Paytm records facilitate revenue collection and the security profiling of citizens in Kashmir and elsewhere. ${ }^{19}$

\section{The Metaphors of Platform Capitalism}

The structural analogy of the emporium is useful, then, for situating the digital "disruption" of India within the longer evolution of retail regimes. By contrast, taking the "digital emporium" as a metaphor allows us to challenge the hegemonic metaphors of "platform capitalism." In the colonial metropoles, the emporium was in its day an unabashed metaphor for the expansive conquests of global trade, bringing an expansive range of material and ethnological goods from the far-flung corners of empire. This etymology was echoed in India's state emporiums of the 1970s, where the diverse products of India's villages' economies were aggregated at the federal center. Then, as now, imperial instincts were driving a centrifugal impulse, as Delhi worked to rationalize and subdue India's federal patchwork. Thus, in both cases, the shared etymology between emporium and imperium frames an explicit metaphor for expansive market integration and territorial commerce. By contrast, the modern-day metaphors associated with the platform economy are slippery and evasive. To begin with, the metaphor of "cloud computing" provided a nonthreatening overlay to the worldwide harvest of information, arguably the greatest power grab in human history. ${ }^{20}$ The accompanying metaphor of the platform, as Tarleton Gillespie has argued, also appears to infer a nonthreatening neutrality, and a multifaceted good, and does so by carefully eliding 
the tensions between the competing functions of its usage. ${ }^{21}$ At one level, the notion of a digital platform is a quasi-technical catchall for an operating environment, carriage system, or a piece of infrastructure. The Web 2.0 era dovetailed this usage with the parallel notion of an "advertising platform," where the platform serves as a vehicle for influence and profit. The liberal notion of an "open platform" softens the edges of this convergence by invoking democratic connotations of meritocratic ambition, free speech, and equal competition.

"Technology companies," as they prefer to be called, have thus reliably deployed the metaphor of the "open platform" to defend themselves against responsibility for the content and consequences of the digital services that they operate. In turn, the critical response to the expanding concentration of platform power has extended the metaphor as coinage of its own critique. As a proponent of the recent analytical concept of "platform capitalism," Nick Srnicek characterizes the new affordances of "platform capitalism" that digital platforms have brought into being. As he puts it,

Platforms, in sum, are a new sort of firm: they are characterized by providing the infrastructure to mediate between different user groups, by displaying monopoly tendencies driven by network effects, by employing cross-subsidisation to draw in different user groups and by having a designed core architecture that that governs the interaction possibilities ... all of these characteristics make platforms key business models for extracting and controlling data...they are an extractive apparatus for data. ${ }^{22}$

By this formulation, the technological metaphors (core architecture, interaction possibilities) converge with capitalist tendencies (monopoly, cross-subsidization) to multiply and monetize "network effects." The underlying goal is to enclose and maximize "data extraction" from the user-base. As such, the platform inculcates novel logics predicated upon the boosting of data-based discovery. Amid the furore surrounding the ethical wants of data mining and the tech-topic proposition of algorithmic culture, it is certainly hard to avoid the extractive logics that now pervade our digital experience. ${ }^{23}$ With the expansion of "platforms" such as Google and Facebook, we have all become acutely aware of the fact that platforms design and exercise their protocols in order to harvest and analyze data. ${ }^{24}$ Whether big or small, aggregators or niche, platforms engage in "alchemical processes" intended to realize surplus value from user data. ${ }^{25}$ This commodification of user data takes many forms, from traditional "market intelligence" to behavioral interventions and the rejuvenated numerology through which predictive analysis proffers computerized modes of divination. ${ }^{26}$ In the wake of the Cambridge Analytica scandal (in which Indian political parties were implicated), our attention has been further drawn to the commercial and political imperatives under which platforms, state, and political actors join hands in exchanging the benefits of these data "resources." It would be naïve to expect otherwise in India, and the role of digital platform strategies in the 2014 and 2019 elections has not escaped the attention of political observers. $^{27}$

The discourse surrounding platforms piles up the metaphors, through extensive combinations with business argot and Marxist terminology. That is, "platforms" constitute the primary apparatus for "mining" the social domain, acquiring and retaining multitudinous users to accumulate quantums of data and realize value. This highly symbolized "value-chain" is taken by Srnicek to be the defining logic of "platform capitalism." ${ }^{28}$ Nonetheless, beyond 
the imperatives of accumulation, the "shopfronts" of the various high-profile platform "brands" also work hard to articulate distinctive service offerings. With these apparent affordances in mind, Srnicek offers a further basic typology of contemporary platforms, through which he identifies:

Advertising platforms ... which extract information on users, undertake a labour of analysis, and then use the products of that process to sell ad space... Cloud platforms... which own the hardware and software of digital-dependent businesses and are renting them out... Industrial platforms... which build the hardware and software necessary to transform traditional manufacturing into internet-connected processes ... Product platforms ... that generate revenue by using other platforms to turn a traditional good into a service and by collecting rent... Lean platforms ... which attempt to reduce their ownership of assets to a minimum and to profit by reducing costs. ${ }^{29}$

On the face of it (or rather the screen), we could readily apply this model to the Indian case, whereby Google and the online editions of The Hindu could both be categorized as "advertising platforms," Tata Sky could be positioned as a "cloud platform," Infosys becomes a provider of "industrial platforms," e-commerce operations such as Flipkart and digital film companies such as UFO Moviez would all be "product platforms," whereas labor-outsourcing operations such as Ola (taxis) and OYO (hotels) can be lumped together as "lean platforms." This sorting seems neat enough, being a typology based upon "what does the firm do?" Srincek's typology thereby attempts to account both for different sources of profits and for the different products and services platforms offer to their users. In practice, however, this neatness is arbitrary, since these various categories do not constitute any definite series. That is, the categories do not operate along a single set of comparable distinctions and are not distinctive from each other. ${ }^{30}$ Consequently, as Srnicek himself notes, various platforms either operate across or simply fall into multiple categories, and equally critically, there is evidence to suggest that the various platforms are functionally and, often, financially dependent upon each other. That is, the market systems constituted within platform models are, like all markets within a true economy, significantly dependent upon their interaction with other markets (and thereby other platforms).

This ecological interdependence between product markets, which Srnicek refers to as "cross-subsidisation," is by no means particular to the platform economy. As with the "monopoly tendencies" of communication, it has been a distinctive feature of media markets for at least a century, in India as much as elsewhere. ${ }^{31}$ Consequently, platforms can only be partially understood as "firms," 'brands "portals," or "shopfront" businesses. These elements are primarily indicative of the ownership, functionality, and retail interface of platforms, which tend to differ in each case. In the Indian setting, attempts to institute platform capitalism necessarily interact with existing modalities of social exchange. Alongside media platforms driven by content, professionally or user-generated, the wider ecology encompasses the expanding infrastructure of digital finance, along with various platforms aggregating informal markets for "services" (such as drivers, guest houses, home security, and deliveries) as well as gray economies (such as second-hand markets and content piracy). ${ }^{32}$ What is more insidious about this experiment, perhaps, is the simultaneous processes through which everyday interaction, sociability, and democracy are being monetized through personal 
communication platforms. Nonetheless, the fundamental commonality between what we are now categorizing as platforms is their formalization of peer-to-peer exchanges within a rule-based system. Arguably, then, their primary characteristics are those of a marketplace, not a firm. Consequently, a market-based approach to media platforms may prove more useful than a firm-based approach when it comes to comprehending the dynamics of India's platform economy.

\section{Market Automata}

I will explore this kind of approach, initially, by exploring what Srnicek calls the "core architecture" and the governance of "interaction possibilities" within platform systems. ${ }^{33}$ Across platform economy as a whole, we see some useful exemplars of the expansion of a "mediated economy" through which an increasing number of market exchanges are aggregated within portals that allow value capture at the transactional level (through data, certainly, but more explicitly through commissions and subscriptions). One of these would be the commissions taken by the hotel booking platform OYO, and another would be the capacity to offer money storage in mobile wallets to underpin banking services and microfinance. E-commerce is, by its very nature, a vast clearing house. These market offerings are distinctive because of their capacity to furnish zero-level entry barriers to market participants. As part of this bargain, platforms outsource transactional costs to participants, enforce arbitrary access conditions, and enclose buyers and sellers within a proprietary system. At the operational level, the inherent conceptualization of platforms around the role of a market "mediator" of peer-to-peer exchanges (as opposed to an owner, buyer, or seller within the relevant market) allows for their "lean" existence as internet portals and their opportunistic location for tax purposes. The programmatic and proprietary logics of these forms of capture suggest that, somewhat unlike earlier media industries, the institutional logic of a platform is not the organization of any productive process per se, but rather the design and population of an automated market system.

Approaching platforms as a set of transactional markets rather than as types of firms encourages some different thinking on "platform capitalism." Not least, it prompts us to reconsider the "stack" of infrastructure as being, simultaneously, a stack of markets and a stack of technologies. ${ }^{34}$ In each phase of development, it has been the commercial potentials of the public internet that have been paramount to the extension of the system, with each additional layer of functionality adding purposefully to the impetus toward commodification. In the 1990s, value was extracted from the communication layer, through the sale of hardware, software subscriptions, data packs, and other forms of access rents. In the 2000s, additional value was being extracted from the distribution layer, through content subscriptions, pay-per-view offerings, UGC, and the bulk of the world's advertising revenues. In the 2010s, further value is being extracted from various forms of piece work, user-tracking, data mining, and the aggregation of commissions exercised over peer-to-peer exchanges. This is the transactional layer where platform businesses operate. It is too narrow, therefore, to explicate platforms as simply data collection companies operating in the guise of service providers. There is a much higher order of integration in play across these layers, where each platform integrates 
multiple products in simultaneous transaction. ${ }^{35}$ While platform logics should by no means be seen as an "outcome" of the so-called "Web 2.0" era, it is at the present technical level that the mass individuation and interoperability of digital systems have allowed platforms to realize opportunities for synchronizing large sets of marketplaces in real time.

Platforms extract different forms of rent from online transactions (whether this is social communication, peer-to-peer selling, or labor exchanges). As digital manifestations of certain "market ideals," platforms are designed to profit from "optimal pricing" and to multiply "friction-free capitalism" among users who are simultaneously producers and consumers. ${ }^{36}$ They are protected from both buyers and sellers by virtue of safe harbor clauses enshrined in (or, as in the Indian case, derived from) the Digital Millennium Copyright Act. By such means, platforms seek to locate themselves in the transactional layer of the digital economy, not simply to benefit from a "lean" operating model, but to avoid being regulated as businesses within the markets they are seeking to encapsulate. If Netflix is not a broadcaster, Paytm is not a bank, NaMo TV is not a news channel, and Amazon is not a retailer, they avoid any regulatory norms save their own, thereby acquiring a sovereign advantage in the relevant market. Platforms have thus claimed the right to operate as essentially privatized markets, under a branded entity that sets its own regulatory norms. As I indicated at the outset, this form of commercial extraterritoriality is hardly unknown to India, nor is the consequent capacity of such players to furnish multiple products and multisided markets. Consequently, the arrival of the Californian East India Companies has been coterminous with the evolution of similar entitles, both within India and across the Asian region (such as Softbank, Alibaba, and Reliance Jio).

Although these various ambitions for market monopoly seem clear enough, we should be wary of schematizing another seemingly tidy structural form as an autonomous reality. In practice, the real analytical benefit of a market-based approach is that it allows us to uncover a great deal of untidiness in India's platform economy. At present, there are around 150 million regular users of broadband in India, which is only 13 percent of the population, and even this level of access is typically intermittent and unstable. The infrastructural layer is fundamentally uneven in terms of coverage, capacity, and access (between metro and rural, between West and East, between rich neighborhoods and poor ones). Even for the one-sixth of the population that has some form of regularized access, irregular electricity supplies, lack of fixed connections, and the limitations of mobile spectrum, all serve to ensure an intermittent digital environment. ${ }^{37}$ Deficiencies in power and speed impede platforms that distribute digital goods, whereas for platforms that seek to facilitate materialized markets, additional infrastructural lacks come into play, not least in road transport. In India, e-commerce operators have been forced to invest in their own distribution infrastructure and to employ a vast host of couriers for delivery. With only half of the population captured within the banking system, and the majority still preferring to avoid debit cards, India's e-commerce operations are forced to handle a lot of cash, thereby increasing the cost and complexity of their operations. The attempt to supercharge the platform economy through the "surgical strike" of demonetization was an economic debacle that demonstrated the dangers of trying to constitute a platform economy by fiat, without due regard for material constraints. ${ }^{38}$ It didn't work. ${ }^{39}$ 
For any realist, India's distribution layer clearly suffers from geographic, temporal, and monetary bottlenecks that should logically impede the expansion of the online market. Nonetheless, India's platform economy continues to expand in the face of such obstacles precisely because labor is incredibly cheap. It is nearly always cheaper than any reliable form of automation. In India, platforms rely on a labor surplus to "absorb" infrastructure bottlenecks. This fact alone undermines a central rationale for platform economies in the industrialized world. ${ }^{40}$ In the Indian context, the major opportunities for platforms lie not in outsourcing labor costs but in capturing large sectors of economic activity that previously operated in the informal economy. Guest houses, street food, rickshaws, drivers, and guards-these are all largely disaggregated cash-based sectors. Their aggregation within platforms constitutes a private-sector "mechanism of legibility," intent upon simultaneously formalizing these markets, "formatting the poor," and bringing them with the ambit of transactional records. ${ }^{41}$ In this respect, the rent capture of informal markets is comparable to the recession economics of " the developed world, where the implicit reliance of platforms on a social surplus that absorbs production costs is explicitly recognised in the utopian deceit of a 'sharing economy'." ${ }^{42}$ In India, however, this sector is far larger and constitutes central rather than surplus capacity. ${ }^{43}$ In a country where low prices and subsistence wages have always been normative, the transactional costs of the digital must be borne by the petty traders that constitute the majority of the lower middle classes. For the platform operators, far smaller profit margins are offset by the sheer numbers involved. It is evident, then, that aggregation of population, not capital, is the guiding principle of platform economy.

\section{Evolutionary Processes}

The evolution of "the stack," as a conjoint commercial and technological process, is an obvious genealogy of the platform economy. It is hardly surprising, therefore, that this pathway dominates our discussion of digital capitalism. ${ }^{44}$ Without doubt, we must account for the ways in which platforms and novel "technology-banks" operate as capital interests in the transactional layer of the platform economy. However, it may be more critical overall to understand their institutional function, which is market capture. From this perspective, the market logics of platforms have evolved along pathways laid down by the marketing industries that guided consumption in the latter half of the twentieth century. Given this lengthy gestation, we need to situate the various domestic and transnational platforms within the ambit of multiple evolutionary processes. ${ }^{45}$ Similarly, as Ramon Lobato observes, we still have to consider a player like Netflix not only within the overarching ecology of platforms but also within the longue durée of the business and usages of television. ${ }^{46}$ Rather than reading "affordances" off the screen, we need to "restore intention" to our understanding of the seemingly inexorable technological and financial trajectories within the platform economy. ${ }^{47}$ For our present purposes, I will attempt to canvas four critical evolutionary pathways that have determined the evolution of platforms: media convergence (between interpersonal and social communication), guided consumption (via market information and audience manipulation), conglomeration (driven by logistic interoperability), and market automation (via the equivalence of data and money exchange). 
From the perspective of user experience, the most obvious evolutionary process is that of convergence between the domains of interpersonal, logistic, and social communication. These domains were long separated by a division of functions enforced by state regulation, thereby guaranteeing neutral logistic functions in the commercial domain and a degree of horizontal (if not vertical) privacy in the domains of personal communication. The convergence of these different usages of media within personalized media devices, along with the wholesale transfer of network operations to the private sector, led unquestionably to a new sensory environment where the flows of personal, political, and commercial information became inextricably mingled. It is the consequences of this process that has driven the popularity of platforms like WhatsApp in India, along with their tragic interaction with village vigilantism, fake news, and electoral politics across the breadth of the country. The converged flows and cellular architecture of such platforms have invigorated the multitude of vernacular public spheres in rural India, bringing these previously informal domains into the digital domain. As much as this has been an exemplar for micro-profits in the developing world, it hasn't been a pretty sight, prompting both WhatsApp and the Government of India to disavow responsibility for the consequences of platform architectures in the hinterlands. ${ }^{48}$

There can be no doubt that the evolving role of the audience in an interactive media apparatus is a critical evolutionary pathway of the platform economy. It has long been recognized that the goods and services, and assets and values operative across media processes are necessarily different from the nineteenth-century model of extraction, labor, manufacture, and sale that has dominated our understanding of "industries." ${ }^{49}$ Media producers must garner audiences for what are largely experiential products (whether their content is expressive or informative in intent). The production of audiences is always a persuasive process. Furthermore, the generation of audience mass provides the basis for communication systems to facilitate wider process of persuasion. As Dallas Smythe noted long ago, media producers were implicated not only in the production of their own advertisement but also in the sale of the audience commodity itself. ${ }^{50}$ Media industries therefore played a central role in the wider project of "guided consumption" that was taken up as an alternative to "planned production" in the mass economies of the twentieth century. As a consequence, they were able to generate not only a market for influence but also a wealth of market information about consumers, which, in turn, generated its own customers. ${ }^{51}$ In an era of individual addressability, platforms converge these functions within a single automated process. Thus, while platforms may seek to fashion an enclosed marketplace (a "one-stop shop") via their "user experience," on the server side they operate multisided markets bringing together numerous clients for market information, all of whom benefit by the existence of the platform in different ways.

The primacy of user data in the platform economy runs in parallel with the long-term evolution of economic planning. In the Indian context, this process is often seen as being marked by the institution of the planning commission in 1950, followed by the rupture of "liberalization" in 1991 and the turn away from industrial planning and toward a consumer-led economy. The major distinction between planning and guiding, often confused with ideological trappings, is simply between producing what people need and giving people what they want. Since both require mediation, this tends in practice to devolve to a choice between giving people what they are told that they need (say, Aadhaar) and giving people what they are told 
to want (say, Amazon). Both are top-down processes, and this is why media platforms like YouTube have been associated with a novel liberation of media content production from the hands of media corporations to the putative benefit of small producers and the general public. ${ }^{52}$ However, it is highly significant in the Indian case that there were scarcely any such media corporations twenty years ago. In fact, there has, over the "liberalization" period, been a clear evolution toward conglomeration via the application of digital technologies. The Indian media economy over the past twenty years has seen private capital taking over the communication domains of the state and subsequently "formalizing" previously disorganized sectors of media business, before moving on to "platformize" other markets for goods and services. In part, this concentration of platform power has occurred because the shift to the digital has come with extremely high infrastructure costs, which only a handful of private interests can bear, and in part because the internal logics of a platform ecology necessitate a high degree of interoperability and mobility across platforms.

Another important point of distinction in the Indian case is that all three layers of the platform economy are being built simultaneously and, in the most part, underwritten by the same actors. Consequently, the interests of platform businesses are more effectively attuned to the interests of India's telecom networks, which is primarily in driving network expansion and increasing data traffic. Equally, it is not by chance that financial entities are the major investors in the platform sector. The guiding ethos of Fintech is to ensure that every peerto-peer transaction generates a commission or deposit. Whereas early proponents of digital technologies emphasized their potentials for reducing transaction costs, the era of platforms has deliberately inverted this logic, precisely because platform businesses make their money on each transaction. This fosters a novel equivalence between airtime, user data, commissions, and digital finance in the platform economy, and thereby signifies the financialization of the social domain on a vast scale. ${ }^{53}$ Fundamentally, the primary goal of platforms as aggregators of peer-to-peer exchanges is to enhance and widen the number, depth, and range of transactions in play. In that respect, the conceptual evolution of computerized markets from the 1970s onward, implemented incrementally from the bourses in the 1980s down to previously informal sectors in the 2010s, is a neglected, but obviously central, evolutionary pathway. One of the consequences of the four converging genealogies is that the major interests behind the platform economy are relatively content-agnostic. They do not particularly care whether the data being circulated are Aamir Khan, Comicstaan, fascist memes, or video calls from a particularly intrusive aunty, as long as transactions of time, data, and money are being captured.

\section{Bundling India}

Almost twenty years ago, Ashish Rajadhyaksha noted that the businesses of making films and selling tickets had become an "alarmingly" small part of the Bollywood industry. ${ }^{54}$ Today, even the expanded multiformat domain of Hindi cinema and its ancillary products is just a small part of a much larger media economy, which itself increasingly appears as a loss-leader for even bigger ambitions. In this milieu, it seems unlikely that dedicated "media platforms" will survive without patronage from the network operators who effectively control 
distribution, and thereby the capacity to underwrite original content production. At the same time, without the perennially loss-making business of expressive content, the lure of the digital is much reduced and clicks and transactions will fall away like a mall without its multiplex. What does this role within a larger bundle of commodities mean for our analytical frame of "media industries"? These are the questions of the moment, but perhaps the invocation of the emporium provides us with some useful pointers toward understanding the commercial logics and path dependencies currently shaping digital marketplaces in India. That is, seeing platforms as extending and converging, rather than producing, their own market trajectories might allow us to more accurately grasp their potentials for reshaping market relationships and expanding marketization within their respective domains. From the nineteenth-century bazaar to the twentieth-century emporium and the twenty-firstcentury platform, India has inspired the sovereign ambitions of companies seeking to diversify their products, build their own transport systems, mint their own coin, write their own laws, collect their own taxes, and determine the rights of producers and consumers.

The unavoidable example at this juncture is not Mark Zuckerberg's Facebook but India's Reliance. Building upon the legacy of Dhirubhai Ambani's astounding success, first in polyester and then in petrochemicals, the diversification undertaken by his two sons, Anil and Mukesh, has been the most potent force in shaping India's media economy over the past two decades. ${ }^{55}$ First of all, it was Anil Ambani who invested his share of India's largest inheritance in cinema, radio, and mobile telecoms through his ADAG Group. In 2015, it was Mukesh Ambani who orchestrated vast levels of investment by Reliance Industries Limited (RIL) into upgrading India's digital infrastructure, some US\$42 billion according to Rahul Mukherjee. ${ }^{56}$ This was accompanied by the launch of Reliance Jio, which provided mobile subscribers with free call plans and data plans far below market costs. Within two years, this undercutting of the existing mobile networks accelerated the uptake of mobile broadband along with the consolidation of the mobile sector to just three major players. ${ }^{57}$ The vast loss-leader of free Jio services and its cheap handsets have captured hundreds of millions of users, thereby creating the user-base for a raft of Jio platform services, including JioMoney, JioChat, and JioTV. ${ }^{58}$ Within two years of entering the market, Reliance Jio has been able to integrate what Rahul Mukherjee calls the "pipes and platforms" of Digital India, easily securing its ambition to become the provider of $5 \mathrm{G}$ networks in India. Despite protestations from competitors and regulators, including the Comptroller and Auditor General (CAG), this vast and rapid acquisition of market power has been actively supported by the Government of India, for whom the partnerships inherent in realizing the infrastructure of Digital India are far more important than the norms of market regulation. The unique capacity of Reliance (with its major holdings across media and retail sectors, and in energy, infrastructure, and finance) to operate at scale at the all-India level makes it a natural partner for developing India's platform economy.

In itself, the Jio story brings to light the territorial logics of the telecom business and the maturation of its convergence with the proprietary logics of platform ecospheres. In the larger dimension, the ever-expanding integration of goods and services under the Reliance flag certainly seems redolent of the imperial commerce of the nineteenth century. Diversification over a thirty-year period from textiles into oil refining, power generation, financial services, telecoms, media and entertainment, grocery stores, and mobile apps and banking has created a multiproduct retail space of astounding proportions. Its instantly recognized 
brand now encloses goods, services, and markets across the breadth of India, allowing the two apex Reliance companies to aggregate economic, social, and political transactions across all major sectors of the economy, including defense. This sweeping set of interests underpins Reliance's emergence as a "national champion" and provides the heft for its working partnerships with transnational capital, expressed in its recently announced alliance with Microsoft and the aim of becoming "India's Huawei." From powering homes and vehicles to laying down fiber networks, Reliance now occupies a central position around which transport, entertainment, and service economies are being reorganized, with its financial infrastructure capable of servicing venture capital markets and everyday mobile payments on its JioMoney platform. As it takes on a critical role in the flagship Digital India program, RIL is closely aligned with the political imperatives of the current Government of India and its technologically inspired vision of reshaping the citizenry. From its trademark skyscraper in South Bombay, Reliance thus has a reasonable claim to the status of a modern-day East India Company, a vast conglomerate easily capable of competing with its international counterparts in their attempts to dominate the markets of a Digital India. Thus, while we could consider Reliance as a "firm" working across Srnicek's typology and beyond, it is, in a larger sense, part of a historically recurring pursuit of paramountcy over India's market systems.

Standing against such ambitions, both domestic and international, is always the questions of what the market will bear, what these vast ambitions will cost, and what the polity will succumb to (i.e., aside from free data). As such, there is always more to consider in platform economies than "capitalism" per se. Indeed, it is by no means clear that platform economies, heavily reliant upon network effects and reciprocity between users, are strictly or solely capitalist in practice. In overtly social platforms, such as matrimonial and personal communication apps, providers such as Shaadi, Tinder, and WhatsApp extract subscriptions and/or commissions from an increasingly mobile, but still significantly feudal, population. In various ways, these examples infer a further characteristic of platform economies: the dis-embedding of social relationships and their re-embedding in new transactional forms. ${ }^{59}$ This implies that these market systems may not be capitalist in the classic sense, since the means of participation (i.e., ownership of the market) is far more central than ownership of the means of production (per se) or profit from outputs (as long as sufficient volumes of transactions are being captured). At the very least, since they rely heavily on the simultaneous operation of reciprocity and redistribution across each network of exchange, my sense is that platforms which transact social economies cannot be solely capitalist. Equally, India's extensive familial economics remain laden with reciprocal exchanges across all socioeconomic classes, and Reliance is no exception to this general rule. Jio's disruptive offering of free airtime and data can also be understood as an effective redistribution of digital capacity, and the equally evident accommodation between Paytm and the Government of India in the "Cashless India" initiative is inextricably tied up with the redistributive functions of taxation and the implementation of India's GST in 2017.

For all these reasons, the notion of platform capitalism may not quite capture the full extent of the "great integration" envisioned through the platform economy model. Such an undertaking requires the market logics of content, of carriage, of service, of labor, of airtime, of user input, of data assets, of convenience, of surveillance, of gratification, of energy, and of sociability to become effectively synchronized. In this larger context, media scholars have to 
consider whether we should, or even can, maintain a distinction between the platformization of an Indian media economy (the aggregation of content-producing and communication industries) and the wider platformization of the increasingly mediated economy of India (the integration of logistical processes, monetary exchanges, and political action). ${ }^{60}$ Evidently, as the complexity of media systems increases, a mediated economy becomes substantially more dependent upon the parallel expansion of the media economy, and vice versa. Equally clearly, the media are now more central to day-to-day social and economic processes than ever before, but it becomes increasingly hard to discern anything we could call a media industry as such. A taxi ride platform that draws profits as much from holding the digital balances of its drivers and riders as it does from its slice of fares is clearly not a media company. Does it become so when it starts providing personalized in-car movie streaming as part of its app service? If Amazon and Reliance are producing music and television content primarily to lure customers into their retail and telecom ecospheres, can they be adequately considered as media companies? Given their scale of operations, perhaps they should simply be characterized as economies in and of themselves, that is, as emporiums.

${ }^{1}$ I wrote previous iterations of this paper for two events: "Digital Emporiums: Platform Capitalism in India," University of Queensland, August 2018, and "Platform Capitalism, Communication and Culture in South Asia," Curtin University, June 2019. These events were funded by the Platform Media Initiative, University of Queensland, and the South Asian Studies Association of Australia (SASAA).

${ }^{2}$ Adrian Athique is program leader in Cultural Studies at the Institute for Advanced Studies in the Humanities (IASH). Adrian's research interests focus on the social, cultural, and economic implications of digital technologies and on the evolution of media cultures in Asia. He is the author of several books, including The Multiplex in India: A Cultural Economy of Urban Leisure (Routledge, 2010, with Douglas Hill), Indian Media (Polity, 2012), Digital Media and Society (Polity, 2013), and Transnational Audiences: Media Reception on a Global Scale (Polity, 2016). Adrian is also editor of the journal Media International Australia, the OUP series, Media Dynamics in South Asia, and The Indian Media Economy (2 vols, Oxford University Press, 2018, with Vibodh Parthasarathi and SV Srinivas) and Digital Transactions in Asia (Routledge, 2019, with Emma Baulch).

${ }^{3}$ Julie E. Cohen, "Law for the Platform Economy," University of California Davis Law Review 51 (2017): 131-204.

${ }^{4}$ See Adrian Athique and Emma Baulch (ed.), Digital Transactions in Asia: Economic, Social and Informational Processes (NY: Routledge, 2019).

${ }^{5}$ See Adrian Athique, Vibodh Parthasarathi, and S. V. Srinivas, The Indian Media Economy: Industrial Dynamics and Cultural Adaptation, vol. 1 (New Delhi: Oxford University Press, 2018), and Adrian Athique, Vibodh Parthasarathi, and S. V. Srinivas, The Indian Media Economy: Market Dynamics and Social Transactions, vol. 2 (New Delhi: Oxford University Press, 2018).

${ }^{6}$ Akshaya Kumar, "Informality in the Time of Platformization," Media Industries Journal, this issue. 
${ }^{7}$ Pradip Thomas, "Notes on the Platformisation of Mainstream Hinduism" (Unpublished paper presented at Digital Emporiums: Platform Capitalism in India, University of Queensland, 13 August 2018.

${ }^{8}$ See Pradip Thomas, The Politics of Digital India (New Delhi: Oxford University Press, 2019).

${ }^{9}$ Pradip Thomas, "Infrastructure and Platform Anxieties in India," in Digital Transactions in Asia: Economic, Social and Informational Processes, ed. Adrian Athique and Emma Baulch (NY: Routledge, 2019), 44-62.

${ }^{10}$ Rahul Mukherjee, "Jio Sparks Disruption 2.0: Infrastructural Imaginaries and Platform Ecosystems in India," New Media E Society 41 (2, 2019): 182.

${ }^{11}$ See Pavan K. Varma, The Great Indian Middle Class (New Delhi: Penguin Books, 1998) and Sanjay Srivastava, Entangled Urbanism: Slum, Gated Community and Shopping Mall in Delhi and Gurgaon (New Delhi: Oxford University Press, 2014).

${ }^{12}$ See Adrian Athique and Douglas Hill, The Multiplex in India: A Cultural Economy of Urban Leisure (NY: Routledge, 2010) and Christine Brosius, India's Middle Class: New Forms of Urban Leisure, Consumption and Prosperity (Delhi: Routledge, 2012).

${ }^{13}$ See S. Banerjee, The Parlour and the Streets: Elite and Popular Culture in NineteenthCentury Calcutta (Calcutta: Seagull, 1989) and Dipesh Chakrabarty, "Open Space/ Public Place: Garbage, Modernity and India," South Asia: Journal of South Asian Studies 14 (1, 1991): 15-31 and R. K. Ray, "Asian Capital in the Age of European Domination: The Rise of the Bazaar, 1800-1914," Modern Asian Studies 29 (3, 1995): 449-554 and Vibodh Parthasarathi and Adrian Athique, "Market Matters: Interdependencies in the Indian Media Economy," Media, Culture \& Society, published electronically August 18, 2019. doi:10.1177/0163443719853495

${ }^{14}$ Ramon Lobato, Netflix Nations: The Geography of Digital Distribution (NY: New York University Press, 2019).

${ }^{15}$ S. V. Srinivas, "Politics in the Age of YouTube: Degraded Images and Small Screen Revolutions," in Asian Video Cultures: In the Penumbra of the Global, ed. Joshua Neves and Bhaskar Sarkar (Durham, NC: Duke University Press, 2017), 217-39.

${ }^{16}$ Ravinder Kumar Verma, Vigneswara Ilavarasan, and Arpan K. Ker, "Sharing Economy and Ratings: An Exploratory Study of Ratings of Ride Hailing Platforms in Delhi, India" (Unpublished paper presented at Platform Capitalism, Communication and Culture in South Asia, Curtin University, 18-19 June 2019).

${ }^{17}$ Adrian Athique, "Digital Transactions in Asia," in Digital Transactions in Asia: Economic, Social and Informational Processes, ed. Adrian Athique and Emma Baulch (NY: Routledge, 2019), 1-22.

${ }^{18}$ Adrian Athique, "A Great Leap of Faith: The Cashless Agenda in Digital India," New Media E Society 21 (8, 2019): 1697-713.

${ }^{19}$ Hrishikesh Arvikar, "Carrier, Content and Consumption: Portfolios of Fear and Risk in Platform News" (Unpublished paper presented at Platform Capitalism, Communication and Culture in South Asia, Curtin University, 18-19 June 2019).

${ }^{20}$ Adrian Athique, Digital Media and Society (Cambridge: Polity, 2013), 245-59.

${ }^{21}$ Tarleton Gillespie, "The Politics of Platforms," New Media \& Society 12 (3, 2010): 347-64.

${ }^{22}$ Nick Srnicek, Platform Capitalism (Cambridge: Polity, 2017), 48. 
${ }^{23}$ Verónica Gago and Sandro Mezzadra, "A Critique of the Extractive Operations of Capital: Toward an Expanded Concept of Extractivism," Rethinking Marxism 29 (4, 2017): 574-91.

${ }^{24}$ Eran Fisher and Yoav Mehozay, "How Algorithms See their Audience: Media Epistemes and the Changing Conception of the Individual," Media, Culture E Society, 42 (8, 1176-1191).

${ }^{25}$ Adrian Athique, "The Dynamics and Potentials of Big Data for Audience Research," Media, Culture \& Society 40 (1, 2018): 56-74.

${ }^{26}$ Ibid., 62.

${ }^{27}$ V. Goel, "In India, Facebook's WhatsApp Plays a Central Role in Elections," New York Times, May 14, 2018. https://www.nytimes.com/2018/05/14/technology/ whatsapp-india-elections.html

${ }^{28}$ Srnicek, Platform Capitalism, 48.

${ }^{29}$ Ibid., 49-50.

${ }^{30}$ Benedict Anderson, The Spectrum of Comparisons: Southeast Asia and the World (London: Verso, 1998).

${ }^{31}$ Parthasarathi and Athique, "Market Matters."

${ }^{32}$ Aswin Punathambekar and Sriram Mohan, ed. Global Digital Cultures: Perspectives from South Asia (Ann Arbor: University of Michigan Press, 2019).

${ }^{33}$ Srnicek, Platform Capitalism, 48.

${ }^{34}$ Benjamin H. Bratton, The Stack: On Software and Sovereignty (Cambridge, MA: MIT Press, 2016).

${ }^{35}$ Adrian Athique, "Integrated Commodities in the Digital Economy," Media, Culture $\mathcal{E}$ Society, published electronically July 18, 2019. doi:10.1177/0163443719861815

${ }^{36}$ As per Bill Gates, The Road Ahead (London: Penguin, 1995).

${ }^{37}$ Pradip Ninan Thomas, Digital India: Understanding Information, Communication and Social Change (New Delhi: SAGE, 2012).

${ }^{38}$ Athique, "A Great Leap of Faith."

${ }^{39}$ See C. R. Reddy, Demonetisation and Black Money (Hyderabad: Orient Blackswan, 2017).

${ }^{40}$ As per Nick Srnicek and Alex Williams, Inventing the Future: Postcapitalism and a World without Work (London: Verso, 2016), and Martin Ford, The Rise of the Robots: Technology and the Threat of Mass Unemployment (NY: Basic Books, 2016).

${ }^{41}$ Bill Maurer, "Mobile Money, Communication and Consumption in the Mobile Payments Space," Journal of Development Studies 48 (5, 2012): 589-604.

${ }^{42}$ As per Arun Sundararajan, The Sharing Economy: The End of Employment and the Rise of Crowd-Based Capitalism (Cambridge, MA: MIT Press, 2016).

${ }^{43}$ See Amit S. Rai, Jugaad Time: Ecologies of Everyday Hacking in India (Chicago, IL: Duke University Press, 2019).

${ }^{44}$ See, for example, Andrew McAfee and Erik Brynjolfsson, Machine, Platform, Crowd: Harnessing Our Digital Future (NY: W. W. Norton, 2017), and Robert W. McChesney, Digital Disconnect: How Capitalism is Turning the Internet against Democracy (NY: The New Press, 2013).

${ }^{45}$ As per Thorstein Veblen, The Theory of Business Enterprise (NY: Charles Scribner's Sons, 1904). 
${ }^{46}$ Ramon Lobato, Netflix Nations.

${ }^{47}$ As per Raymond Williams, Television: Technology and Cultural Form (London: Collins, 1974).

${ }^{48}$ Ravi Sundaram, "Circulation Takes Command? The Sensory Infrastructure of the Mobile Phone" (paper presented at Digital Transactions in Asia, Queensland University of Technology, August 8-10, 2017).

${ }^{49}$ See Scott Lash and John Urry, Economies of Signs and Space (London: SAGE, 1994).

${ }^{50}$ Dallas Smythe, "Communications: Blindspot of Western Marxism," Canadian Journal of Political and Society Theory 1 (3, 1977): 1-28.

${ }^{51}$ Paul F. Lazarsfeld, "Remarks on Administrative and Critical Communications Research," Studies in Philosophy and Social Science 9 (1941): 2-16.

${ }^{52}$ Notably by Jean Burgess and Joshua Green, You Tube: Online Video and Participatory Culture (Cambridge: Polity, 2009) and Stuart Cunningham and David Craig, "Online Entertainment: A New Wave of Media Globalization?" International Journal of Communication 10 (2016): 5409-425.

${ }^{53}$ See Bill Maurer, How Would You Like to Pay? How Technology Is Changing the Future of Money (Durham, NC: Duke University Press, 2015).

${ }^{54}$ Ashish Rajadhyaksha, "The 'Bollywoodization' of the Indian Cinema: Cultural Nationalism in a Global Arena," Inter-Asia Cultural Studies 4 (1, 2003): 25-39.

${ }^{55}$ Hamish McDonald, The Polyester Prince: The Rise of Dhirubhai Ambani (Melbourne: Allen \& Unwin, 1998).

${ }^{56}$ Mukherjee, "Jio Sparks Disruption 2.0," 176.

${ }^{57}$ Peter Curwen, "Reliance Jio Forces the Indian Mobile Market to Restructure," Digital Policy, Regulation and Governance 20 (1, 2018): 99-102.

${ }^{58}$ Mukherjee, "Jio Sparks Disruption 2.0," 177.

${ }^{59}$ As per Karl Polanyi, The Great Transformation: Political and Economic Origins of Our Time (Boston, MA: Beacon Press, 1944).

${ }^{60}$ Athique, Parthasarathi, and Srinivas, The Indian Media Economy, vol. 1.

\section{Bibliography}

Aiyar, Shankar. Aadhaar: The Biometric History of India's 12-Digit Revolution. Delhi: Westland, 2017.

Anderson, Benedict. The Spectrum of Comparisons: Southeast Asia and the World. London: Verso, 1998.

Arvikar, Hrishikesh. "Carrier, Content and Consumption: Portfolios of Fear and Risk in Platform News." Unpublished paper presented at Platform Capitalism, Communication and Culture in South Asia, Curtin University, June 2019.

Athique, Adrian. "The Dynamics and Potentials of Big Data for Audience Research." Media, Culture E Society 40, no. 1 (2018): 56-74. 
Athique, Adrian. "Digital Transactions in Asia." In Digital Transactions in Asia: Social, Economic and Informational Processes, edited by Adrian Athique and Emma Baulch, 1-22. New York: Routledge, 2019.

Athique, Adrian. "A Great Leap of Faith: The Cashless Agenda in Digital India." New Media $\mathcal{E}$ Society 21, no. 8 (2019): 1697-713.

Athique, Adrian. "Integrated Commodities in the Digital Economy." Media, Culture E Society. Published electronically July 18, 2019. doi:10.1177/0163443719853495

Athique, Adrian, and Douglas Hill. The Multiplex in India: A Cultural Economy of Urban Leisure. New York: Routledge, 2010.

Athique, Adrian, and Emma Baulch (eds). Digital Transactions in Asia: Economic, Social and Informational Processes. New York: Routledge, 2019.

Athique, Adrian, Vibodh Parthasarathi, and S. V. Srinivas. The Indian Media Economy: Industrial Dynamics and Cultural Adaptation, vol. 1. New Delhi: Oxford University Press, 2018.

Athique, Adrian, Vibodh Parthasarathi, and S. V. Srinivas. The Indian Media Economy: Market Dynamics and Social Transactions, vol. 2. New Delhi: Oxford University Press, 2018.

Banerjee, S. The Parlour and the Streets: Elite and Popular Culture in Nineteenth-Century. Calcutta: Seagull, 1989.

Booth, Gregory D. "A Long Tail in the Digital Age: Music Commerce and the Mobile Platform in India." Asian Music 48, no. 1 (2017): 85-113.

Bratton, Benjamin H. The Stack: On Software and Sovereignty. Cambridge, MA: MIT Press, 2016.

Brosius, Christine. India's Middle Class: New Forms of Urban Leisure, Consumption and Prosperity. Delhi: Routledge, 2012.

Burgess, Jean, and Joshua Green. You Tube: Online Video and Participatory Culture. Cambridge: Polity, 2009.

Chakrabarty, Dipesh. "Open Space/Public Place: Garbage, Modernity and India." South Asia: Journal of South Asian Studies 14, no. 1 (1991): 15-31.

Cohen, Julie E. "Law for the Platform Economy." University of California Davis Law Review 51 (2017): 131-204.

Cunningham, Stuart, and David Craig. "Online Entertainment: A New Wave of Media Globalization?" International Journal of Communication 10 (2016): 5409-425.

Curwen, Peter. "Reliance Jio Forces the Indian Mobile Market to Restructure." Digital Policy, Regulation and Governance 20, no. 1 (2018): 99-102.

Fisher, Eran, and Yoav Mehozay. "How Algorithms See Their Audience: Media Epistemes and the Changing Conception of the Individual." Media, Culture E Society. 41 no. 8 (2010): $1176-1191$.

Fitzgerald, Scott. "Over the Top Video Services in India: Media Imperialism after Globalization." Media Industries Journal. 6 (2, 2019). 
Ford, Martin. The Rise of the Robots: Technology and the Threat of Mass Unemployment. New York: Basic Books, 2016.

Gago, Verónica, and Sandro Mezzadra. "A Critique of the Extractive Operations of Capital: Toward an Expanded Concept of Extractivism." Rethinking Marxism 29, no. 4 (2017): 574-91.

Gates, Bill. The Road Ahead. London: Penguin, 1995.

Gillespie, Tarleton. "The Politics of Platforms." New Media \& Society 12, no. 3 (2010): 347-64.

Goel, V. "In India, Facebook's WhatsApp Plays a Central Role in Elections." New York Times, May 14, 2018. https://www.nytimes.com/2018/05/14/technology/whatsapp-indiaelections.html.

Hill, Douglas, and Adrian Athique. "The Role of Off Shore Financial Centres in Indian Telecoms." In The Indian Media Economy: Industrial Dynamics and Cultural Adaptation, vol. 1, edited by Adrian Athique, Vibodh Parthasarathi, and S. V. Srinivas, 66-92. New Delhi: Oxford University Press, 2018.

Jenkins, Henry. Convergence Culture: Where Old and New Media Collide. New York: New York University Press, 2006.

Jha, Shishir K., and NirajMankund. "Examining Digital Competencies within the Entertainment Industry." In The Indian Media Economy: Market Dynamics and Social Transactions, vol. 2, edited by Adrian Athique, Vibodh Parthasarathi, and S. V. Srinivas, 80-98. New Delhi: Oxford University Press, 2018.

Kumar, Akshaya. "Informality in the Time of Platformization." Media Industries Journal, this issue.

Lash, Scott, and John Urry. Economies of Signs and Space. London: SAGE, 1994.

Lazarsfeld, Paul F. "Remarks on Administrative and Critical Communications Research." Studies in Philosophy and Social Science 9 (1941): 2-16.

Lobato, Ramon. Netflix Nations: The Geography of Digital Distribution. New York: New York University Press, 2019.

Lobato, Ramon. "The OTT TV Box as a Diasporic Media Platform." Media Industries Journal. 6 , no. 2 (2019).

Maurer, Bill. How Would You like to Pay? How Technology Is Changing the Future of Money. Durham, NC: Duke University Press, 2015.

Maurer, Bill. "Mobile Money, Communication and Consumption in the Mobile Payments Space." Journal of Development Studies 48, no. 5 (2012): 589-604.

McAfee, Andrew, and Erik Brynjolfsson. Machine, Platform, Crowd: Harnessing Our Digital Future. New York: W. W. Norton, 2017.

McChesney, Robert W. Digital Disconnect: How Capitalism is Turning the Internet against Democracy. New York: The New Press. 2013. 
McDonald, Hamish. The Polyester Prince: The Rise of Dhirubhai Ambani. Melbourne: Allen \& Unwin, 1998.

Mukherjee, Rahul. "Jio Sparks Disruption 2.0: Infrastructural Imaginaries and Platform Ecosystems in 'Digital India'." Media, Culture \& Society 41, no. 2 (2019): 175-95.

Parthasarathi, Vibodh. "Market Dynamics of the Media Economy." In The Indian Media Economy: Market Dynamics and Social Transactions, vol. 2, edited by Adrian Athique, Vibodh Parthasarathi, and S. V. Srinivas, 1-22. New Delhi: Oxford University Press, 2018.

Parthasarathi, Vibodh, and Adrian Athique. "Market Matters: Interdependencies in the Indian Media Economy." Media, Culture E Society. Published electronically August 18, 2019. doi:10.1177/0163443719853495

Parthasarathi, Vibodh, Arshad Amanullah, and Susan Koshy. "Digitalization as Formalization: A View from below." International Journal of Digital Television 7, no. 2 (2016): 155-71.

Polanyi, Karl. The Great Transformation: Political and Economic Origins of Our Time. Boston, MA: Beacon Press, 1944.

Punathambekar, Aswin, and Sriram Mohan, eds. Global Digital Cultures: Perspectives from South Asia. Ann Arbor: University of Michigan Press, 2019.

Rai, Amit S. Jugaad Time: Ecologies of Everyday Hacking in India. Chicago, IL: Duke University Press, 2019.

Rajadhyaksha, Ashish. "The 'Bollywoodization' of the Indian Cinema: Cultural Nationalism in a Global Arena." Inter-Asia Cultural Studies 4, no. 1 (2003): 25-39.

Ray, R. K. "Asian Capital in the Age of European Domination: The Rise of the Bazaar, 1800-1914." Modern Asian Studies 29, no. 3 (1995): 449-554.

Reddy, C. R. Demonetisation and Black Money. Hyderabad: Orient Blackswan, 2017.

Rodrigues, Usha M., and Michael Niemann. "Social Media as a Platform for Incessant Political Communication: A Case Study of Modi's "Clean India" Campaign." International Journal of Communication 11 (2017): 23.

Smythe, Dallas. "Communications: Blindspot of Western Marxism." Canadian Journal of Political and Society Theory 1, no. 3 (1977): 1-28.

Srnicek, Nick. Platform Capitalism. Cambridge: Polity, 2017.

Srnicek, Nick, and Alex Williams. Inventing the Future: Postcapitalism and a World without Work. London: Verso, 2016.

Srinivas, S. V. "Politics in the Age of YouTube: Degraded Images and Small Screen Revolutions." In Asian Video Cultures: In the Penumbra of the Global, edited by Joshua Neves and Bhaskar Sarkar, 217-39. Durham, NC: Duke University Press, 2017.

Srivastava, Sanjay. Entangled Urbanism: Slum, Gated Community and Shopping Mall in Delhi and Gurgaon. New Delhi: Oxford University Press, 2014. 
Sundaram, Ravi. "Circulation Takes Command? The Sensory infrastructure of the Mobile Phone." Paper presented at Digital Transactions in Asia, Queensland University of Technology, August 8-10, 2017.

Sundararajan, Arun. The Sharing Economy: The End of Employment and the Rise of CrowdBased Capitalism. Cambridge, MA: MIT Press, 2016.

Thomas, Pradip. Digital India: Understanding Information, Communication and Social Change. New Delhi: SAGE, 2012.

Thomas, Pradip. "Infrastructure and Platform Anxieties in India." In Digital Transactions in Asia: Economic, Social and Informational Processes, edited by Adrian Athique and Emma Baulch, 44-62. New York: Routledge, 2019.

Thomas, Pradip. "Notes on the Platformisation of Mainstream Hinduism." Unpublished paper presented at Digital Emporiums: Platform Capitalism in India, University of Queensland, October 2018.

Thomas, Pradip. The Politics of Digital India. New Delhi: Oxford University Press, 2019.

Varma, Pavan K. The Great Indian Middle Class. New Delhi: Penguin Books, 1998.

Veblen, Thorstein. The Theory of Business Enterprise. New York: Charles Scribner's Sons, 1904.

Verma, Ravinder Kumar, Vigneswara Ilavarasan, and Arpan K. Ker. "Sharing Economy and Ratings: An Exploratory Study of Ratings of Ride Hailing Platforms in Delhi, India." (Unpublished paper presented at Platform Capitalism, Communication and Culture in South Asia, Curtin University, June 2019).

Williams, Raymond. Television: Technology and Cultural Form. London: Collins, 1974.

Winseck, Dwayne. "The Geopolitical Economy of the Global Internet Infrastructure." Journal of Information Policy 7 (2017): 228-67. 
